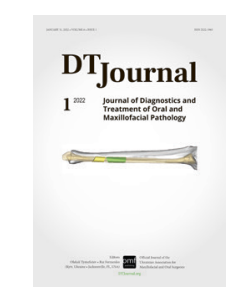

\title{
EDITORIAL
}

\section{It Takes the Entire Healthcare World to End a Pandemic}

\author{
Evangelos G. Kilipiris
}

Infectious diseases know no borders, and neither does the knowledge needed to fight them. -Unknown author

The novel coronavirus, SARS-CoV-2, and the disease it causes, COVID-19, have driven the entire interconnected world for perhaps the first time in modern history to focus on solving a single problem. Globally, two years within this pandemic, physicians, scientists, healthcare leaders, governments, and citizens seek answers to a threat whose entire dimensions remain largely unknown. Experts are working together inside and outside hospitals, laboratories, and healthcare facilities to find the interventions that might best address the current health crisis. This outbreak has demonstrated in real-time how the mobilization of a global health crisis coalition can serve the global public good. Every medical specialty has something to give and something to gain in searching for answers to these burning questions. Oral and maxillofacial surgeons worldwide routinely share information and collaborate across borders.

But all of this is not new. Because, as impressive as this progress is, the world needs more and faster

Director, Journal Development Department, Bratislava, Slovak Republic.

Corresponding author's address: National Institute of Children's Diseases and Faculty of Medicine at Comenius University, 1 Limbova Street, Bratislava 83340, Slovak Republic.

E-mail:varonos@live.co.uk action.

In recent years increased geopolitical tensions and competition have also affected the collaborative nature of the global scientific enterprise. Fractured governments and their citizens tended to view health institutions more through a competitive rather than a cooperative lens. And in a global pandemic where the value of open collaboration is obvious, they are signaling that this emergency is yet another vehicle for competition rather than coordination.

The magnitude of this moment calls for the sharing of expertise and cooperation among physicians of different specialties from all nations and for informed, evidence-based, coordinated responses from national healthcare bodies and the national and global institutions of today, which will much change on the other side of the crisis.

Much more remains to be done to establish a highlevel engagement and practical cooperation. However, the global Oral and Maxillofacial Surgery community is prepared for that. Our international scientific family entered this crisis with a strong foundation of shared objectives and interconnection with clear identification and demarcation of our comparative strengths and joint forces. One that we have built and

Please cite this article as: Kilipiris EG. It takes the entire healthcare world to end a pandemic. J Diagn Treat Oral Maxillofac Pathol 2022;6(1):1-2.

Available online 17 January 2022

https://doi.org/10.23999/j.dtomp.2022.1.1

(C) 2022 OMF Publishing, LLC. This is an open access article under the CC BY license (http://creativecommons.org/licenses/by-nc/4.0/). 
maintained through collaborative projects, exchanges, international meetings, and engaging dialogues. All of them are potent links that are always beneficial, but they become crucial in times of crisis.

Personally, the relationships that I have cultivated with colleagues, scientists, and researchers over the years have helped me navigate beyond official channels in the uncharted territory of this multidimensional crisis, and this experience demonstrated the importance of sharing lessons learned. I boldly believe that international collaboration in science offers both the best hope for a solution to the current crisis and a model for all institutions to follow to build a better and safer shared future in Oral and Maxillofacial Surgery more precisely and in healthcare more broadly.

Because this pandemic won't end for anyone until it ends for everyone. 